\title{
Building damage characteristics based on surveyed data and fragility curves of the 2011 Great East Japan tsunami
}

\author{
Anawat Suppasri • Erick Mas • Ingrid Charvet • Rashmin Gunasekera • \\ Kentaro Imai · Yo Fukutani · Yoshi Abe · Fumihiko Imamura
}

Received: 10 August 2012/Accepted: 3 November 2012/Published online: 18 November 2012

(C) The Author(s) 2012. This article is published with open access at Springerlink.com

\begin{abstract}
A large amount of buildings was damaged or destroyed by the 2011 Great East Japan tsunami. Numerous field surveys were conducted in order to collect the tsunami inundation extents and building damage data in the affected areas. Therefore, this event provides us with one of the most complete data set among tsunami events in history. In this study, fragility functions are derived using data provided by the Ministry of Land, Infrastructure and Transportation of Japan, with more than 250,000 structures surveyed. The set of data has details on damage level, structural material, number of stories per building and location (town). This information is crucial to the understanding of the causes of building damage, as differences in structural characteristics and building location can be taken into
\end{abstract}

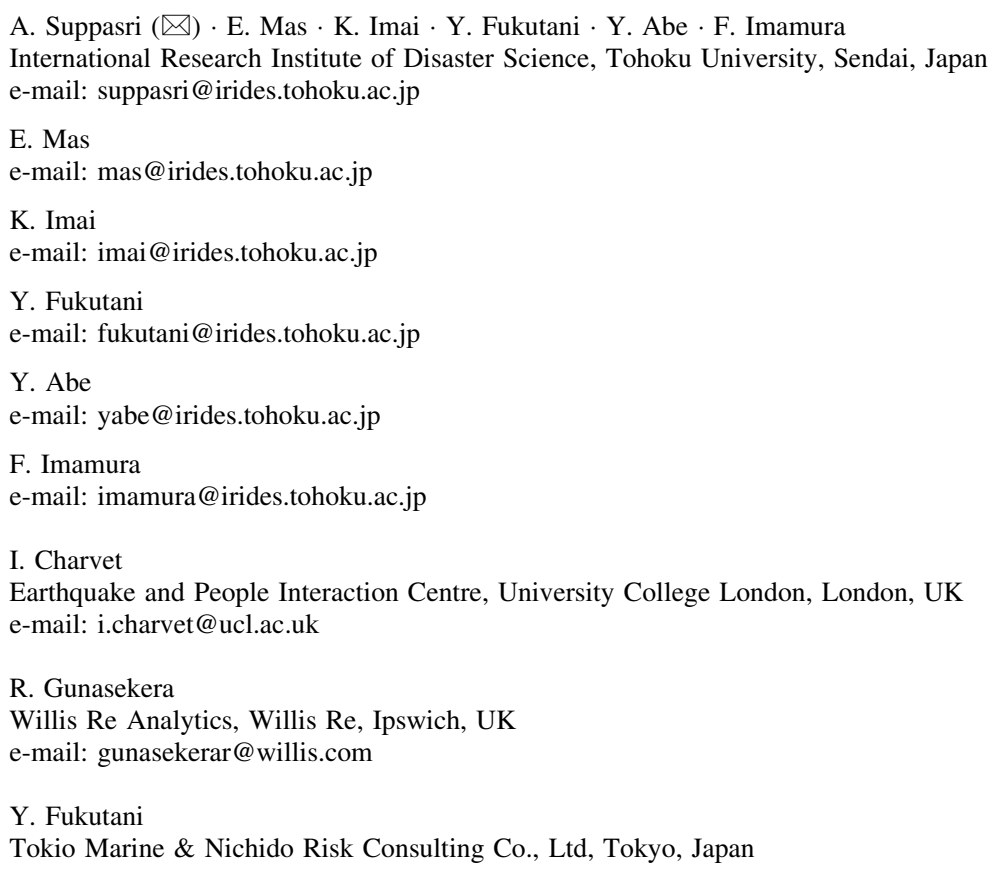


account in the damage probability analysis. Using least squares regression, different sets of fragility curves are derived to demonstrate the influence of structural material, number of stories and coastal topography on building damage levels. The results show a better resistant performance of reinforced concrete and steel buildings over wood or masonry buildings. Also, buildings taller than two stories were confirmed to be much stronger than the buildings of one or two stories. The damage characteristic due to the coastal topography based on limited number of data in town locations is also shortly discussed here. At the same tsunami inundation depth, buildings along the Sanriku ria coast were much greater damaged than buildings from the plain coast in Sendai. The difference in damage states can be explained by the faster flow velocities in the ria coast at the same inundation depth. These findings are key to support better future building damage assessments, land use management and disaster planning.

Keywords The 2011 Great East Japan tsunami · Building damage - Fragility curve

\section{Introduction}

The East coast of Japan was extensively affected by the 2011 Great east Japan tsunami, with more than 400,000 buildings damaged or destroyed (National Police Agency 2011). The extensive damage directly impacted infrastructure system and the economy due to the loss of houses, offices, markets and industries. In order to reduce such dramatic consequences on the population, it is crucial to improve our understanding of building damage characteristics due to a tsunami.

The influence of structural material and number of stories on the building resistance to tsunami inundation has been highlighted in a number of studies, such as Ruangrassamee et al. (2006), Dominey-Howes and Papathoma (2007), Reese et al. (2007, 2011), Arikawa (2009), Koshimura et al. (2009b), Lukkunaprasit et al. (2010), Matsutomi and Harada (2010), Murao and Nakazato (2010), Leone et al. (2011), Suppasri et al. (2011) and Valencia et al. (2011). They agreed that reinforced concrete (RC) or steel structures are stronger than wood or masonry structures and that multiple-story buildings (over three floors) are stronger than low-rise buildings (one or two floors). However, the studies above that attempted to analyze damage by using field data were limited by the amount of damaged building data available and surveyed tsunami inundation depths in the sample, as well as a restricted damage classification when using aerial imagery (the damage states that can be identified are only collapsed or standing).

In addition, to this date, the effects of coastal topography on building damage during a tsunami attack have not been quantitatively investigated. The Tohoku (Northeast) area in Japan comprises two main coastal morphologies; the ria coast in Sanriku area in Iwate prefecture and North of Miyagi prefecture, and the plain coast in the South of Miyagi prefecture and Fukushima prefecture. Based on many examples of observed historical tsunamis, the Sanriku coast is known to be capable of amplifying tsunami waves because of their V-shape ria coast (Suppasri et al. 2012d). Therefore, it might be reasonable to expect that these amplified waves would trigger, for the same inundation depth inland, higher damage levels in the ria coast than in the plain area. However, until the 2011 tsunami, there were no data available to substantiate this hypothesis.

This study uses the complete data set of more than 250,000 damaged buildings with surveyed tsunami inundation depths. The damage inspection compiled damage level, structural material, number of stories, inundation depth and location of structures (no 
coordinates, only the name of the town). Using least squares regression, different sets of fragility curves are derived to demonstrate the influence of structural material, number of stories and coastal topography on building damage levels.

\section{Review of literature on building damage due to tsunami inundation}

Early studies on building damage in Japan collected damage data from historical tsunamis and proposed threshold depths for collapse as damage criteria. For instance, wooden houses and reinforced concrete building may collapse if the tsunami inundation depth is $>2$ and $8 \mathrm{~m}$, respectively (Shuto 1993). Damage criteria for each different structural material against a range of tsunami inundation depths have been used since then, and some studies updated those results such as Matsutomi and Shuto (1994) and Matsutomi and Harada (2010). However, these results are not sufficient in order to perform detailed building damage assessment: This type of damage criteria cannot provide information such as damage probability for a given inundation depth.

More studies on building damage due to tsunamis were conducted after the 2004 Indian Ocean tsunami, which caused widespread destruction in many Asian countries and caused small damage to some African countries. Using the 2004 tsunami data, Ruangrassamee et al. (2006) concluded that an inundation depth of only $2 \mathrm{~m}$ can be enough to completely destroy a wooden house, confirming the aforementioned result from Shuto (1993). Reese et al. (2007) found the same threshold for unreinforced brick buildings (i.e., destruction above a 2-m inundation depth), which strongly indicates that this damage criterion is key to predict survival/destruction of most common types of unreinforced buildings. This conclusion is consistent with later results, for example, Valencia et al. (2011) found that a type $\mathrm{C}$ building (brick with reinforced column and masonry filling) in Banda Aceh, Indonesia, would sustain only light damage at an inundation depth of $<3 \mathrm{~m}$, moderate damage at depths $>3 \mathrm{~m}$ and the total destruction at depths $>7 \mathrm{~m}$. Similar observations using mean damage levels can be found in the study of Leone et al. (2011).

According to Ruangrassamee et al. (2006), inundation depth of $2 \mathrm{~m}$ might cause damage to only the secondary members of an RC building (e.g., a wall or roof), while a 3-m inundation depth might damage its primary members (e.g., columns and beams), and a 7-m depth would be able to completely destroy an RC building. This information is consistent with Valencia et al. (2011) and Reese et al. (2011). On the other hand, Reese et al. (2007) proposed damage criteria based on the data from the 2006 Java tsunami which agreed with the previous studies.

Matsutomi and Harada (2010) concluded that a $1.5 \mathrm{~m}$ and a $2.0 \mathrm{~m}$ depth would partially and completely damage a wooden house, respectively, and that a depth of more than $8.0 \mathrm{~m}$ would completely damage an RC building. However, due to differences in construction practices and standards in different countries, it was found that Japanese wooden houses are comparatively stronger; moderate, major and complete damage will occur when the inundation depth is greater than 3.0, 4.0 and $4.5 \mathrm{~m}$, respectively (Suppasri et al. 2012a, c). Further experimental studies for structural behavior due to tsunami load were done by Arikawa (2009) and Lukkunaprasit et al. (2010) in order to further investigate tsunami depths/loads on structures and the induced damage which is consistent with the previous findings.

In the literature, other characteristics of buildings have not been clearly evaluated for damage probability and related to the tsunami inundation depth yet. One of the 
contributions in this paper is to present the damage probability of structures with different number of floors for the various depths of tsunami inundation.

For example, a different approach to the fragility curves presented here is the PTVA method (Papathoma et al. 2003; Papathoma and Dominey-Howes 2003; Dominey-Howes et al. 2010) where the idea of "damage probability" - actually vulnerability -is measured based on a ranking and weight factor of several characteristics related to the building (i.e., material, number of floors, surroundings, sea defense). The PTVA method aims at taking into account as many influential variables as possible by using a qualitative evaluation of the building characteristics and its environment, to assess building vulnerability. However, the method used in this paper (fragility curves) allows for a quantitative evaluation of damage probability related to tsunami features and characteristics of the structure (i.e., material, height, natural environment).

To address the shortcomings of previous building damage criteria/thresholds, a statistical approach to calculate detailed building damage probability was adopted by (Koshimura et al. 2009b) and consisted in the development of fragility functions. Tsunami fragility functions give the probability of reaching or exceeding a given damage state, for a range of values of the demand parameter(s). This method was first applied in earthquake engineering studies for seismic damage assessment (i.e., Porter et al. 2007) and has now been adapted to tsunami damage probability estimation. For the case of a tsunami, the fragility curve defines a relationship between damage probability and tsunami flow characteristics inland such as inundation depth, current velocity and hydrodynamic force (i.e., the demand parameters). The damage can be classified using field survey data or visual interpretation of high-resolution satellite images. The tsunami flow characteristics can be obtained by a field survey of inundation depth and by the numerical simulation in a very fine grid for current velocity and hydrodynamic force.

This new method was then adopted using the 2004 tsunami data in Banda Aceh, Indonesia, (number of buildings, $N=48,910$ ) (Koshimura et al. 2009c) and then in Phang Nga and Phuket, Thailand $(N=4,596)$ (Suppasri et al. 2011). It was also applied to the 1993 Okushiri Island tsunami $(N=769)$ (Koshimura et al. 2009a) and the 2009 American Samoa tsunami $(N=6,239)$ (Gokon et al. 2011). These studies developed the fragility curves using a combined damage data from satellite image and tsunami data from numerical simulation. Other tsunami fragility curves developed from survey data were proposed for Thailand $(N=120)$ (Foytong and Ruangrassamee 2007), Sri Lanka $(N=1,535)$ (Murao and Nakazato 2010), Banda Aceh, Indonesia $(N=2,576)$ (Valencia et al. 2011), American Samoa, Samoa, $(N=201)$ (Reese et al. 2011) and east Japan $(N=150)$ (Suppasri et al. 2012c). Mas et al. (2012a) developed the fragility curves using satellite image and survey data for the 2010 Chile tsunami $(N=915)$. A summary and comparison of these tsunami fragility curves can be found at Suppasri et al. (2012b, c) and Mas et al. (2012b).

These results reflected the buildings' structural performance and damage probability at each tsunami inundation depth. They confirmed that out of the building types studied, RC buildings had the lowest damage probability followed by masonry and wood buildings. However, the influence of the number of stories and coastal topography on building damage due to tsunami is still unclear because there were too few damaged building data and detailed tsunami field surveys similar to the MLIT survey were never conducted before. Furthermore, a limitation of these developed fragility curves is that the impact of floating debris is complex and cannot be included in the numerical model. Some buildings might have been heavily damaged if they were hit by floating debris, even though the inundation depth and current velocity recorded were small. 


\section{Data and method}

The data analyzed in this study were obtained during field surveys and were compiled by the Ministry of Land, Infrastructure and Transportation of Japan (MLIT) in the form of an aggregated database. Building damage and tsunami inundation depth data were used to derive fragility functions, using a least squares regression and a lognormal probability density function. The tsunami inundation depth for each building was obtained by (1) MLIT survey, (2) other survey reports, (3) picture/video or other visual materials, (4) eyewitness accounts and (5) other methods. The data were first analyzed for all buildings, then split between structural material, number of stories and location along the coast, to capture and explain potential variations in damage predictions.

\subsection{Damaged building data}

The MLIT conducted field surveys of damaged buildings and tsunami inundation depth (Tohoku Earthquake Tsunami Joint Survey Group 2011) in the whole tsunami-affected areas covering seven provinces (Hokkaido, Aomori, Iwate, Miyagi, Fukushima, Ibaraki and Chiba). The main affected areas by the 2011 Great East Japan tsunami are shown in Fig. 1. The data of damage inspection are available through the MLIT website (MLIT 2012) with 251,301 buildings in their database. Each damaged building was measured and classified according to its damage level (six levels were defined by MLIT), structural material (reinforced concrete (RC), steel, wood or other light weight structure such as soil or block) and number of stories (one, two or three stories and higher). The damage levels are as follows: (1) minor damage, (2) moderate damage, (3) major damage, (4) complete damage, (5) collapse and (6) washed away. Descriptions of each damage level are summarized in Table 1. The measure of tsunami inundation depths on an interval of $0.5 \mathrm{~m}$ is shown together with each damage level (Table 2); this information can be simplified and graphically represented as shown in Fig. 2. Tsunami fragility curves will be developed for each affected area and compared to demonstrate a boundary of probable maximum and minimum damage probability for each damage level, structural material and number of stories at a specific inundation depth.

\subsection{Developing the fragility curve}

The building damage probabilities for each damage level were calculated and shown against a median value within a range of every $0.5-\mathrm{m}$ inundation depth. Linear regression analysis was performed to develop the fragility function. The cumulative probability $P$ of occurrence of damage is given either by Eq. (1) or by (2):

$$
\begin{gathered}
P(x)=\Phi\left[\frac{x-\mu}{\sigma}\right] \\
P(x)=\Phi\left[\frac{\ln x-\mu^{\prime}}{\sigma^{\prime}}\right]
\end{gathered}
$$

where $\Phi$ represents the standardized normal distribution function, $x$ stands for the hydrodynamic feature of tsunami used as demand parameter (e.g., inundation depth, current velocity or hydrodynamic force), and $\mu$ and $\sigma$ ( $\mu^{\prime}$ and $\sigma^{\prime}$ ) represents the mean and standard deviation of $x(\ln x)$, respectively. Two statistical parameters of fragility function, $\mu$ and $\sigma\left(\mu^{\prime}\right.$ and $\left.\sigma^{\prime}\right)$, are obtained by plotting $x(\ln x)$ against the inverse of $\Phi$ on normal or 


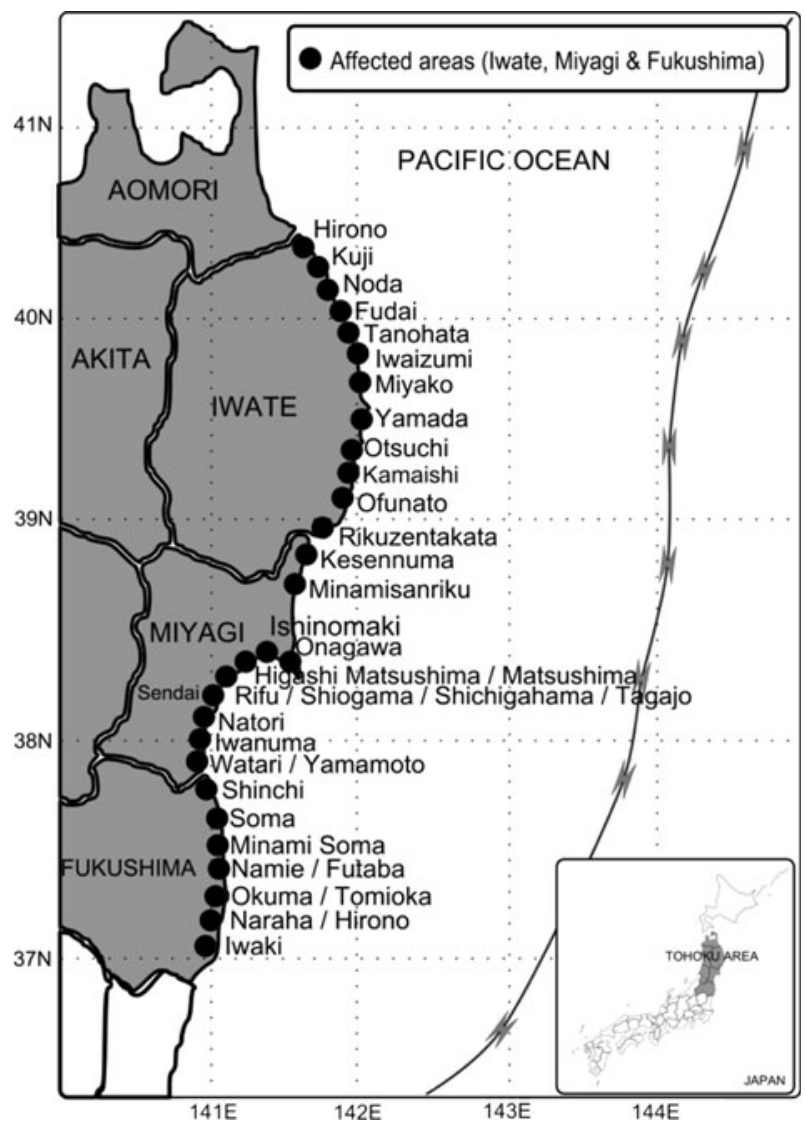

Fig. 1 Mainly affected areas by the 2011 Great East Japan tsunami

Table 1 Damage levels, classification description and condition of building

\begin{tabular}{|c|c|c|c|}
\hline $\begin{array}{l}\text { Damage } \\
\text { level }\end{array}$ & Classification & Description & Condition \\
\hline 1 & $\begin{array}{l}\text { Minor } \\
\text { damage }\end{array}$ & $\begin{array}{l}\text { There is no significant structural or non- } \\
\text { structural damage, possibly only minor } \\
\text { flooding }\end{array}$ & $\begin{array}{l}\text { Possible to be use immediately } \\
\text { after minor floor and wall clean } \\
\text { up }\end{array}$ \\
\hline 2 & $\begin{array}{r}\text { Moderate } \\
\text { damage }\end{array}$ & $\begin{array}{l}\text { Slight damages to non-structural } \\
\text { components }\end{array}$ & $\begin{array}{l}\text { Possible to be use after moderate } \\
\text { reparation }\end{array}$ \\
\hline 3 & $\begin{array}{l}\text { Major } \\
\text { damage }\end{array}$ & $\begin{array}{l}\text { Heavy damages to some walls but no } \\
\text { damages in columns }\end{array}$ & $\begin{array}{l}\text { Possible to be use after major } \\
\text { reparations }\end{array}$ \\
\hline 4 & $\begin{array}{l}\text { Complete } \\
\text { damage }\end{array}$ & $\begin{array}{l}\text { Heavy damages to several walls and some } \\
\text { columns }\end{array}$ & $\begin{array}{l}\text { Possible to be use after a complete } \\
\text { reparation and retrofitting }\end{array}$ \\
\hline 5 & Collapsed & $\begin{array}{l}\text { Destructive damage to walls (more than } \\
\text { half of wall density) and several columns } \\
\text { (bend or destroyed) }\end{array}$ & $\begin{array}{l}\text { Loss of functionality (system } \\
\text { collapse). Non-repairable or } \\
\text { great cost for retrofitting }\end{array}$ \\
\hline 6 & $\begin{array}{c}\text { Washed } \\
\text { away }\end{array}$ & $\begin{array}{l}\text { Washed away, only foundation remained, } \\
\text { total overturned }\end{array}$ & $\begin{array}{l}\text { Non-repairable, requires total } \\
\text { reconstruction }\end{array}$ \\
\hline
\end{tabular}


Table 2 Example of building damage data from the whole affected area in Japan

\begin{tabular}{|c|c|c|c|c|c|c|c|c|c|}
\hline \multirow{3}{*}{$\begin{array}{l}\text { Inundation } \\
\text { depth (m) }\end{array}$} & \multicolumn{9}{|c|}{ Number of building } \\
\hline & \multicolumn{6}{|c|}{ Damaged building } & \multirow[t]{2}{*}{ No damage } & \multirow[t]{2}{*}{ N/A } & \multirow[t]{2}{*}{ Total } \\
\hline & Level 6 & Level 5 & Level 4 & Level 3 & Level 2 & Level 1 & & & \\
\hline$\sim 0.5$ & 320 & 516 & 106 & 1,852 & 10,934 & 10,977 & 8,043 & 181 & 32,929 \\
\hline $0.5-1.0$ & 457 & 805 & 290 & 7,847 & 16,853 & 6,152 & 2,447 & 146 & 34,997 \\
\hline $1.0-1.5$ & 791 & 1,828 & 612 & 11,766 & 8,788 & 2,602 & 945 & 194 & 27,526 \\
\hline $1.5-2.0$ & 1,757 & 3,934 & 1,066 & 9,683 & 2,842 & 942 & 491 & 173 & 20,888 \\
\hline $2.0-2.5$ & 2,830 & 5,709 & 1,135 & 3,407 & 1,601 & 352 & 165 & 126 & 15,325 \\
\hline $2.5-3.0$ & 4,362 & 5,596 & 1,320 & 1,223 & 1,065 & 137 & 113 & 58 & 13,874 \\
\hline $3.0-3.5$ & 5,655 & 4,224 & 1,046 & 857 & 423 & 50 & 73 & 13 & 12,341 \\
\hline $3.5-4.0$ & 6,736 & 3,229 & 797 & 710 & 151 & 26 & 66 & 7 & 11,722 \\
\hline $4.0-4.5$ & 7,062 & 2,038 & 652 & 514 & 113 & 15 & 46 & 7 & 10,447 \\
\hline $4.5-5.0$ & 6,383 & 1,416 & 433 & 251 & 67 & 13 & 40 & 31 & 8,634 \\
\hline $5.0-5.5$ & 5,492 & 870 & 376 & 127 & 41 & 14 & 26 & 6 & 6,952 \\
\hline $5.5-6.0$ & 5,304 & 641 & 327 & 125 & 30 & 6 & 15 & 4 & 6,452 \\
\hline $6.0-6.5$ & 4,851 & 459 & 213 & 59 & 25 & 5 & 15 & 9 & 5,636 \\
\hline $6.5-7.0$ & 3,796 & 403 & 161 & 41 & 17 & 4 & 13 & 1 & 4,436 \\
\hline $7.0-7.5$ & 3,459 & 299 & 129 & 37 & 16 & 3 & 13 & & 3,956 \\
\hline $7.5-8.0$ & 3,238 & 261 & 101 & 55 & 6 & 1 & 11 & 4 & 3,677 \\
\hline $8.0-8.5$ & 2,705 & 212 & 94 & 61 & 3 & & 9 & & 3,084 \\
\hline $8.5-9.0$ & 2,441 & 175 & 59 & 18 & 3 & & 9 & 1 & 2,706 \\
\hline $9.0-9.5$ & 2,441 & 167 & 103 & 14 & 2 & & 11 & 3 & 2,741 \\
\hline $9.5-10.0$ & 2,621 & 179 & 113 & 6 & 3 & & 2 & 3 & 2,927 \\
\hline $10.0-10.5$ & 2,135 & 89 & 46 & 3 & 3 & 2 & 7 & & 2,285 \\
\hline $10.5-11.0$ & 1,951 & 88 & 33 & 5 & & & 7 & & 2,084 \\
\hline $11.0-11.5$ & 1,627 & 80 & 27 & 5 & 2 & & 3 & & 1,744 \\
\hline $11.5-12.0$ & 1,561 & 44 & 13 & 3 & 2 & & & & 1,623 \\
\hline $12.0-12.5$ & 1,422 & 51 & 15 & 2 & 1 & & 1 & & 1,492 \\
\hline $12.5-13.0$ & 1,471 & 58 & 25 & 3 & & & & & 1,557 \\
\hline $13.0-13.5$ & 1,691 & 75 & 19 & 1 & 1 & & 1 & & 1,788 \\
\hline $13.5-14.0$ & 1,651 & 62 & 25 & 1 & 1 & 1 & 4 & & 1,745 \\
\hline $14.0-14.5$ & 1,568 & 51 & 21 & 2 & & & 2 & & 1,644 \\
\hline $14.5-15.0$ & 1,027 & 41 & 13 & 2 & 1 & & 1 & & 1,085 \\
\hline $15.0-15.5$ & 680 & 23 & 6 & 3 & & & 1 & & 713 \\
\hline $15.5-16.0$ & 590 & 43 & 9 & 3 & 3 & & 1 & & 649 \\
\hline $16.0-16.5$ & 372 & 37 & 3 & 2 & & & 2 & & 416 \\
\hline $16.5-17.0$ & 425 & 31 & 6 & 4 & & & & & 466 \\
\hline $17.0-17.5$ & 400 & 41 & 16 & 2 & 1 & & & & 460 \\
\hline $17.5-18.0$ & 406 & 37 & 11 & & 1 & & & & 455 \\
\hline $18.0-18.5$ & 176 & 5 & 4 & & & & & & 185 \\
\hline $18.5-19.0$ & 127 & 5 & 1 & 1 & & & & & 134 \\
\hline $19.0-19.5$ & 84 & 3 & & & & & & & 87 \\
\hline $19.5-20.0$ & 79 & 11 & 2 & & & & & & 92 \\
\hline $20.0 \sim$ & 276 & 28 & 10 & & & & & & 314 \\
\hline
\end{tabular}




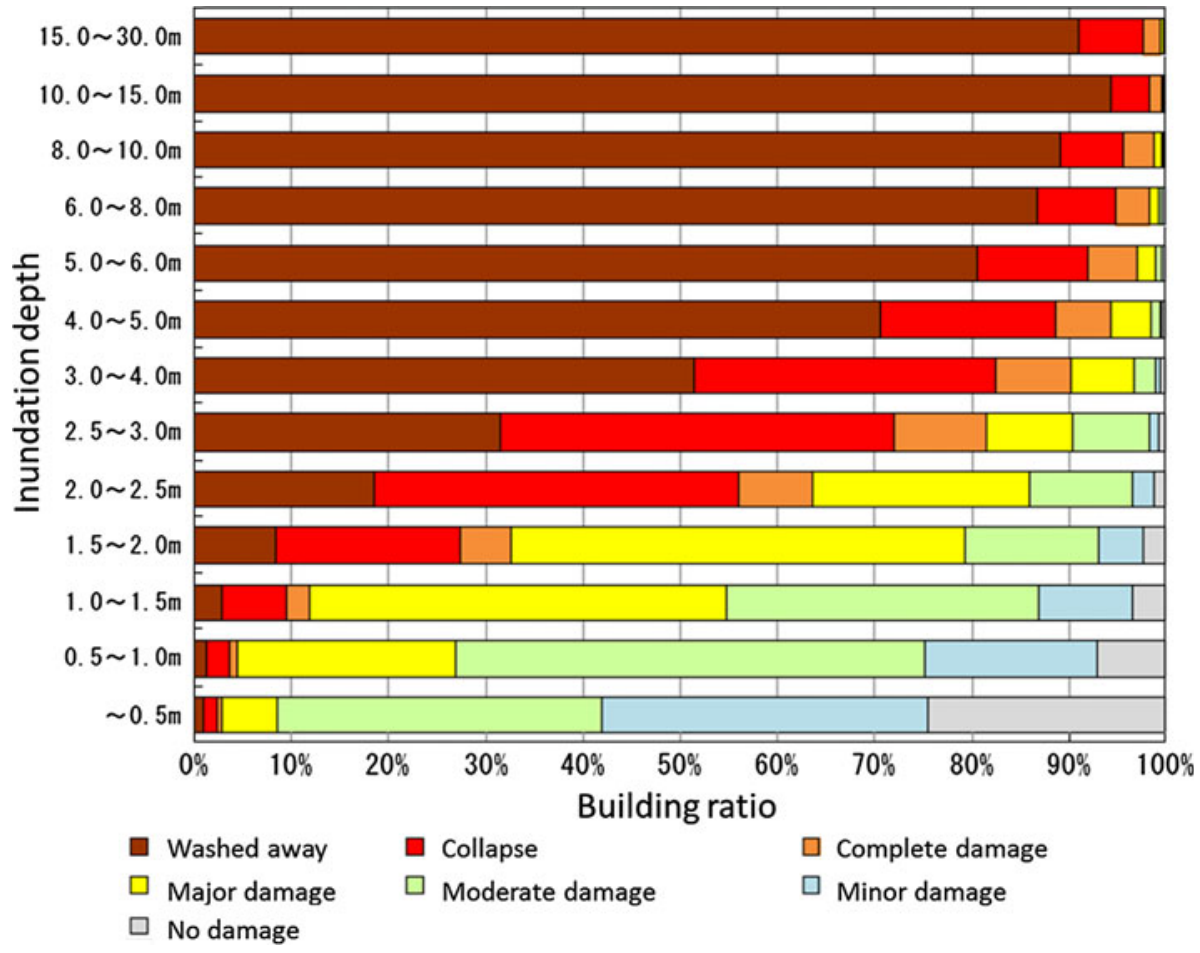

Fig. 2 Distribution of the total 251,301 building data surveyed by MLIT (2012)

lognormal probability papers, and performing least-square fitting of this plot (Fig. 3). Consequently, two parameters are obtained by taking the intercept $\left(=\mu\right.$ or $\left.\mu^{\prime}\right)$ and the angular coefficient $\left(=\sigma\right.$ or $\left.\sigma^{\prime}\right)$ in Eq. (3) or (4):

$$
\begin{gathered}
x=\sigma \Phi^{-1}+\mu \\
\ln x=\sigma^{\prime} \Phi^{-1}+\mu^{\prime}
\end{gathered}
$$

Throughout the regression analysis, the parameters are determined to obtain the best fit (in the least squares sense) of fragility curves with respect to the inundation depth.

\section{Results}

Building damage characteristics can be discussed using the building damage data and the developed fragility curves in different perspective. The analysis aims to reflect potential differences in damage probabilities due to: (1) damage level only (all buildings), (2) structural material, (3) number of stories and (4) coastal topography.

\subsection{Damage level}

Building damage data for the whole of Japan from 2011 Great East Japan tsunami event was summarized by MLIT were used to plot six different damage levels (Table 1) without separation of structural material, number of stories or coastal topography as shown in 
Fig. 3 Example of the plot on log-normal probability paper

Fig. 4 Tsunami fragility curves for the whole area (Chiba to Aomori) with mixed structural material in different damage levels ( $1=$ Minor damage, $2=$ Moderate damage, 3 = Major damage, $4=$ Complete damage, $5=$ Collapse and $6=$ Washed away)
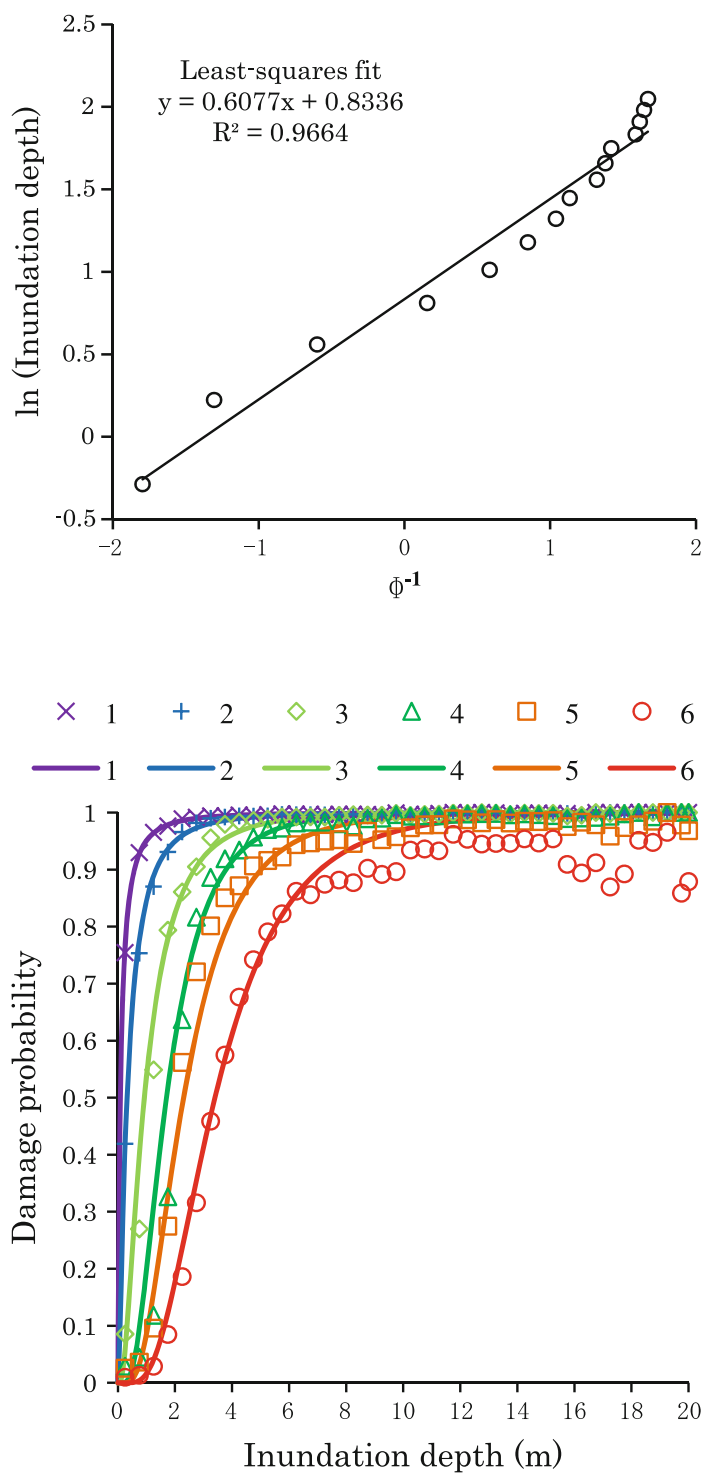

Fig. 4. It is reasonable that the expected damage probability will be higher for lower damage level classes at the same inundation depth reference point. For example, the damage probability for level 2 (moderate damage or greater) should be higher than the damage probability for level 5 (collapse or greater). The results show for mixed structural material that the damage probability at an inundation depth equal to $2 \mathrm{~m}$ for damage levels $1-6$ is roughly $0.2,0.4,0.6,0.8,0.95$ and 1.0 , respectively. The $2-\mathrm{m}$ inundation depth is a key threshold value because the damage probability for each damage level is nearly the same. According to Fig. 4, the probability of damage occurrence reaches their maximum value for all type of damage levels when the inundation depth exceeds $10 \mathrm{~m}$. 

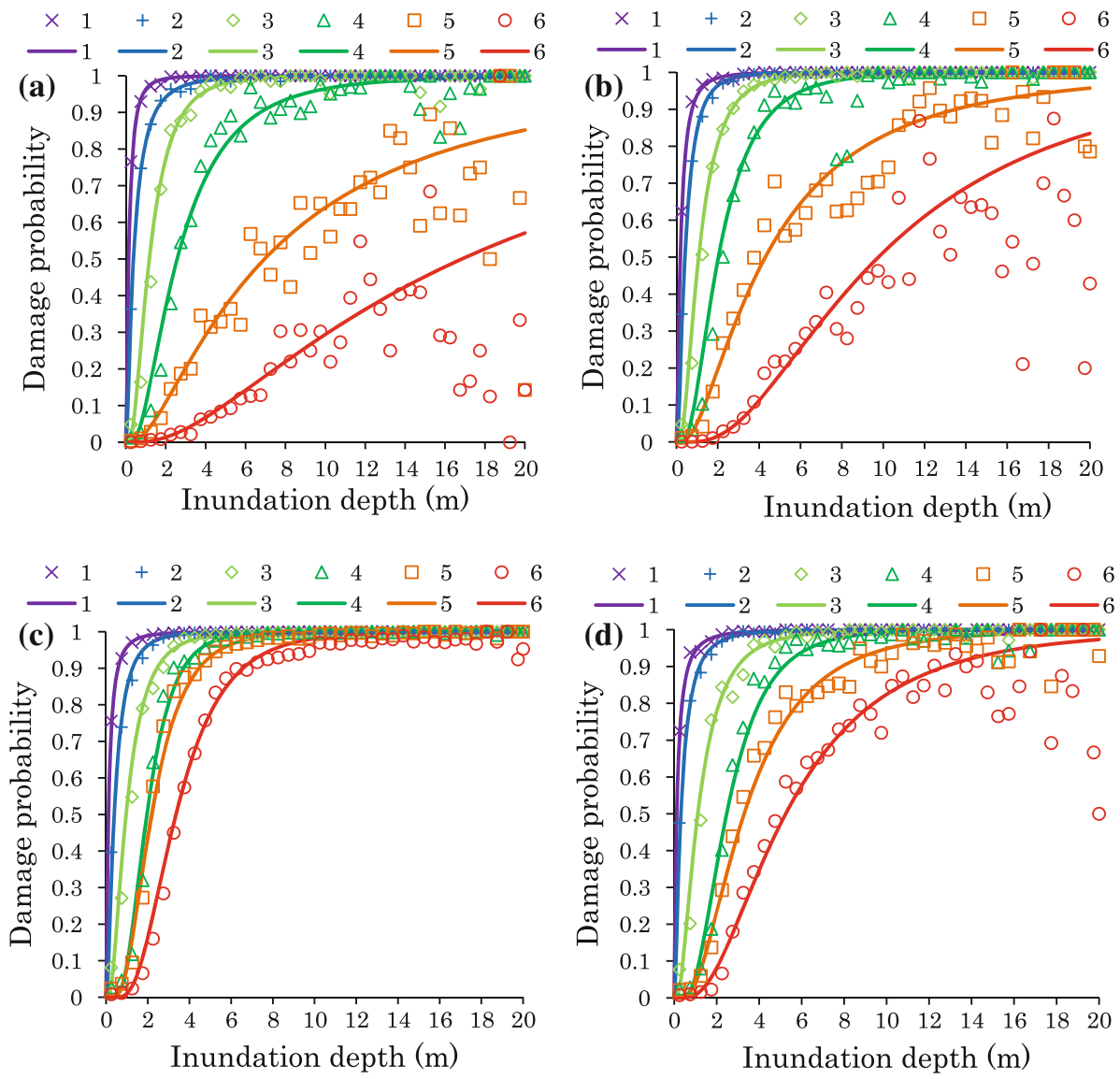

Fig. 5 Tsunami fragility curves for the whole area (Chiba to Aomori) with separated structural material a RC, b Steel, c Wood and d Masonry

\subsection{Structural material}

Using the data of the whole affected areas in Japan, we separated it into different structural materials. The results based on the structural materials are shown in Fig. 5a-d. For most of the structural material data-except for wood-when inundation depths were $>10-15 \mathrm{~m}$, the sample size of surveyed number of buildings to calculate the damage probability was comparatively less. Since data prepared by MLIT were summarized at fixed intervals of inundation depth-every $0.5 \mathrm{~m}$ depth, there is less number of surveyed buildings within intervals over $10 \mathrm{~m}$ depth, compared to lower inundation depths. Therefore, in some cases, we discounted the data on higher depth intervals to avoid underestimating the damage probability.

It can be seen from the results in Fig. 5 that $\mathrm{RC}$ is the strongest structure followed by steel, masonry and wood. For example, a probability that 2-m inundation depth would damage buildings as level 5 (collapsed and washed away) for RC, steel, masonry and wood is about $0.1,0.2,0.25$ and 0.45 , respectively. All wood buildings and most lightweight buildings were washed away when inundation depth was $>10 \mathrm{~m}$ while only $50 \%$ or less 
for steel and RC. It is noticed that the damage probability for level 1-4 is not very different for the different structural material: for steel, wood and masonry buildings, the damage probability for level 4 varies around $0.4-0.5$. These results indicate that RC and steel are structural materials that play very important role in preventing a building to be collapsed or washed away.

\subsection{Number of stories}

The MLIT data set for the whole Japan was then separated again for different number of stories categorized as one story, two stories and three stories or higher. This data set was only provided for two structural types (RC and wood). Results are shown in Fig. 6a-f and strongly support the findings of previous studies that a building with high number of stories is stronger than the ones of one or two stories. This can be explained by the fact that the supporting members of buildings with a large number of stories are designed to withstand greater gravity loads and therefore are more resistant.

Building damage characteristics based on the number of stories are discussed for every inundation depth of $3 \mathrm{~m}$ which we assumed equal to the floor height. Damage level 5 (collapsed or washed away) is given as an example to compare the differences in damage probability.

For RC building, an inundation depth of $3 \mathrm{~m}$ caused damage by $0.30,0.20$ and 0.15 for one, two and three stories or more, respectively. An inundation depth of $6 \mathrm{~m}$ increased the damage probability to $0.6,0.5$ and 0.25 , respectively. Inundation depths of 9-15 m, which would totally overtop one and two-story buildings, caused 0.7-0.9 damage probability, while only $0.45-0.70$ for three stories or more.

However, for buildings of wood construction, a 3-m inundation depth caused $0.75,0.60$ and 0.40 damage probability to one, two and three stories or more, respectively. Unlike RC building, a 6-m inundation depth caused nearly 1.0 damage probability to one and twostory buildings that were overtopped and as high as 0.8 for buildings higher than three stories. Finally, a 9-m inundation depth is enough to destroy or wash away wood building no matter of the number of stories.

The differences in damage probability between one-story and two-story buildings were not very large. However, especially for wood buildings, the damage probability is significantly reduced for the case of three stories or more. For example, a 3-m inundation depth caused 0.45 and 0.30 probability for level 6 (washed away) but almost zero for wood buildings over three stories. An inundation depth of $6 \mathrm{~m}$ could definitely wash away wood buildings of one or two stories, but only about 0.5 probability for wood buildings over three stories. In addition, damage probability for damage levels 5 and 6 also greatly decreases in case of RC building having at least three stories. Therefore, for a given structural material, buildings having three stories or more might withstand better the impacts of tsunami for the same tsunami height. In other words, the damage is not only controlled by the tsunami height, but also dependent on the number of stories and structural class of the building hit.

\subsection{Coastal topography}

The damage probabilities and fragility curves shown in previous section represent an average of the data for the whole tsunami-affected areas by the 2011 event. In this section, we are interested in investigating the effects of two different coastal topographies on building damage. 


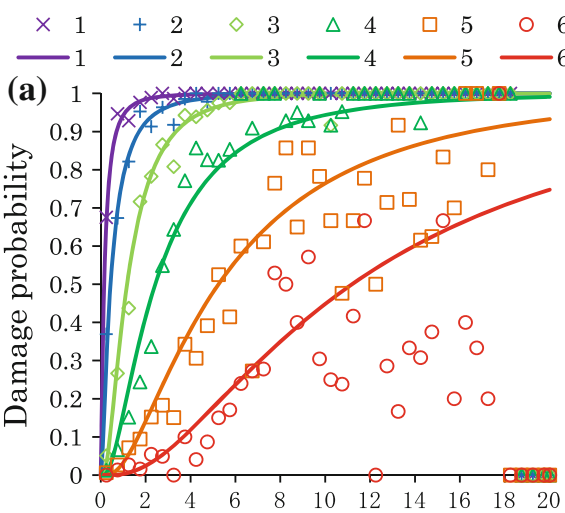

Inundation depth (m)
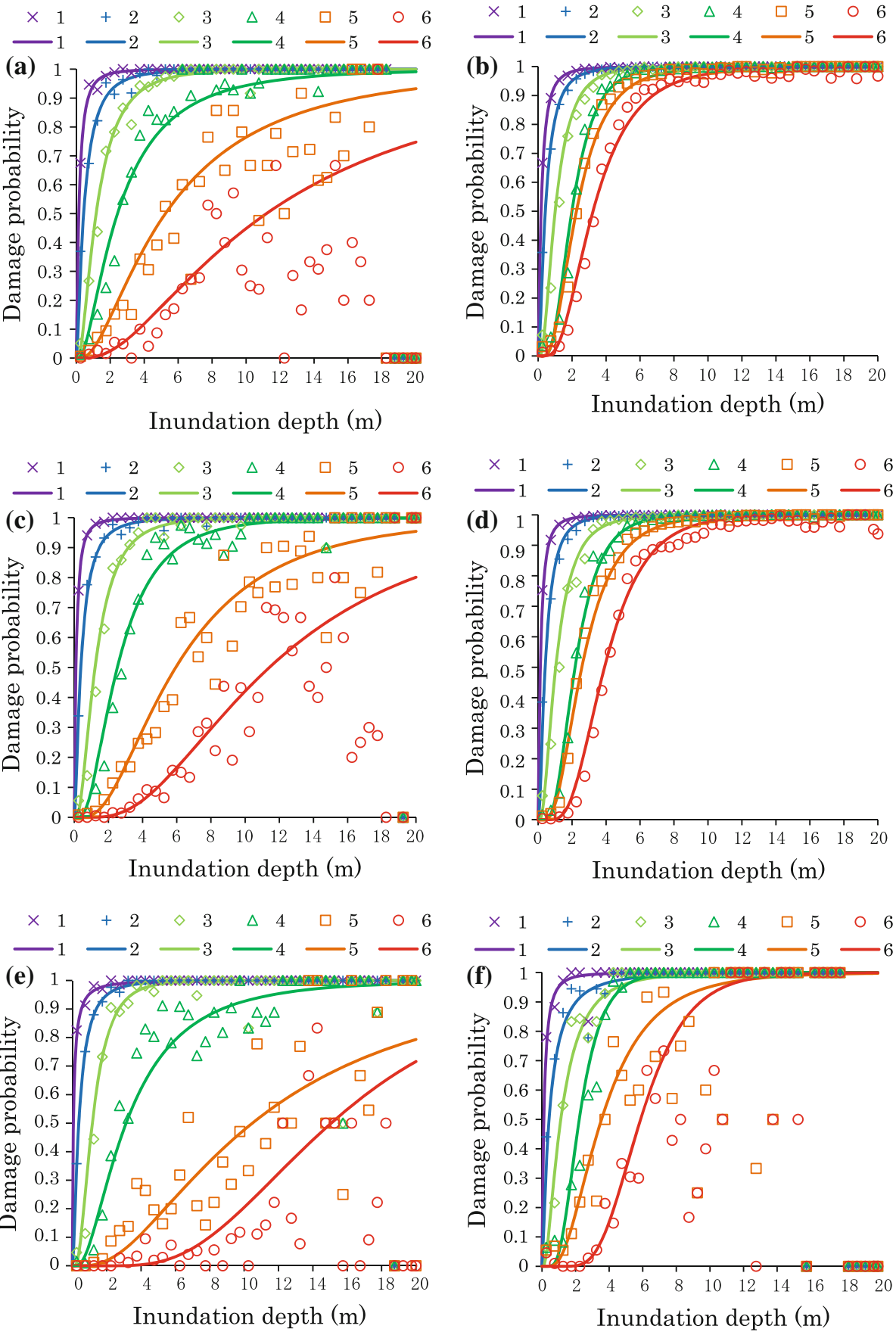

Fig. 6 Tsunami fragility curves for the whole area (Chiba to Aomori) with separated structural material and number of stories a RC -1 story, b Wood - 1 story, $\mathbf{c}$ RC -2 stories, d, Wood -2 stories, e RC -3 stories or more and $\mathbf{f}$ Wood- 3 stories or more 
The same data provided by MLIT (2012) along the region from Miyako in Sanriku area to Minami Soma in Fukushima were used for the analysis. As highlighted in Sect. 4.2, structural characteristics play a major role in a building's ability to withstand tsunami loads. Therefore, data were separated according to the buildings' structural material: RC, steel, wood and masonry. Figures $7 \mathrm{a}-\mathrm{d}$ and $8 \mathrm{a}-\mathrm{d}$ show the possible range of damage probability for each type of material at damage levels 5 and 6 (washed away and collapsed), respectively. The reason why these two damage levels were selected is that their damage probabilities are greatly affected by structural material, compared to lower damage states. It is noted that we could not plot all results from all tsunami-affected areas because of the availability of data for each location.

In general, the variation of damage probability at the same inundation depth can be 0.2 or less when inundation depth is $<1-2 \mathrm{~m}$ for all types of structural material shown in Fig. 7a-d for damage level 6. However, this will be as high as 0.9 for damage level 5 at 2to 3-m inundation depth shown in Fig. 8a-d. The variation is the largest in RC structures, followed by steel, masonry and wood if we considered the difference between the upper and lower lines perpendicular with regard to the average curve shown by the solid line in all figures. The difference in damage probability is on average \pm 0.1 for wood (Figs. 7c, 8 c) and masonry (Figs. 7d, 8d) and as high as \pm 0.2 for steel (Figs. 7b, 8b) and \pm 0.3 for RC (Figs. 7a, 8a).

In order to compare the effects of the two different coastal topographies, we need a data set from a location having both plain and ria coast. Ishinomaki city was the only heavily damaged area that geographically combined both mentioned topographies (Fig. 9). Building damage and tsunami inundation depth data (mixed structural material) provided by Ishinomaki city which is separated into two categories (plain coast and ria coast) were used to create the fragility curves. The building damage was classified into five levels similar to the data provided by MLIT, washed away, collapsed, major damage, moderate damage and minor damage for every $0.5-\mathrm{m}$ interval of the measured maximum tsunami inundation depth. Therefore, building damage probability for each damage level can be plotted against the inundation depth.

Tsunami fragility curves for plain and ria coasts in Ishinomaki city are shown in Fig. 10a, b, respectively. It can be seen that, for example, damage probability for washed away at 2-m inundation depth is $<0.05$ in plain coast, while about 0.4 in ria coast. The damage probability in plain coast increases to 0.5 at $5-\mathrm{m}$ inundation depth, while the damage probability is 0.8 for ria coast. It can be noticed that the damage probability for the plain coast abruptly increases from 3- to 6-m inundation depth and becomes greater than the ria coast when the inundation depth reaches nearly $7 \mathrm{~m}$. Finally, it reaches almost 1.0 when the inundation depth is equal to $8 \mathrm{~m}$. On the other hand, the damage probability for the ria coast abruptly increases from 0.5 - to 3-m inundation depths and slightly increases until the damage probability is nearly 1.0 when the inundation depth is about $10 \mathrm{~m}$. These results show that the coastal topography differences between the plain coast and the ria coast noticeably affect the damage probabilities due to tsunami. The damage probabilities for buildings in the ria coast generally increase more and are higher than those in the plain coast.

\section{Discussion and conclusions}

By using one of the largest and most complete tsunami-induced damage data set provided by MLIT for the 2011 Great East Japan tsunami, this study clarified the importance of 

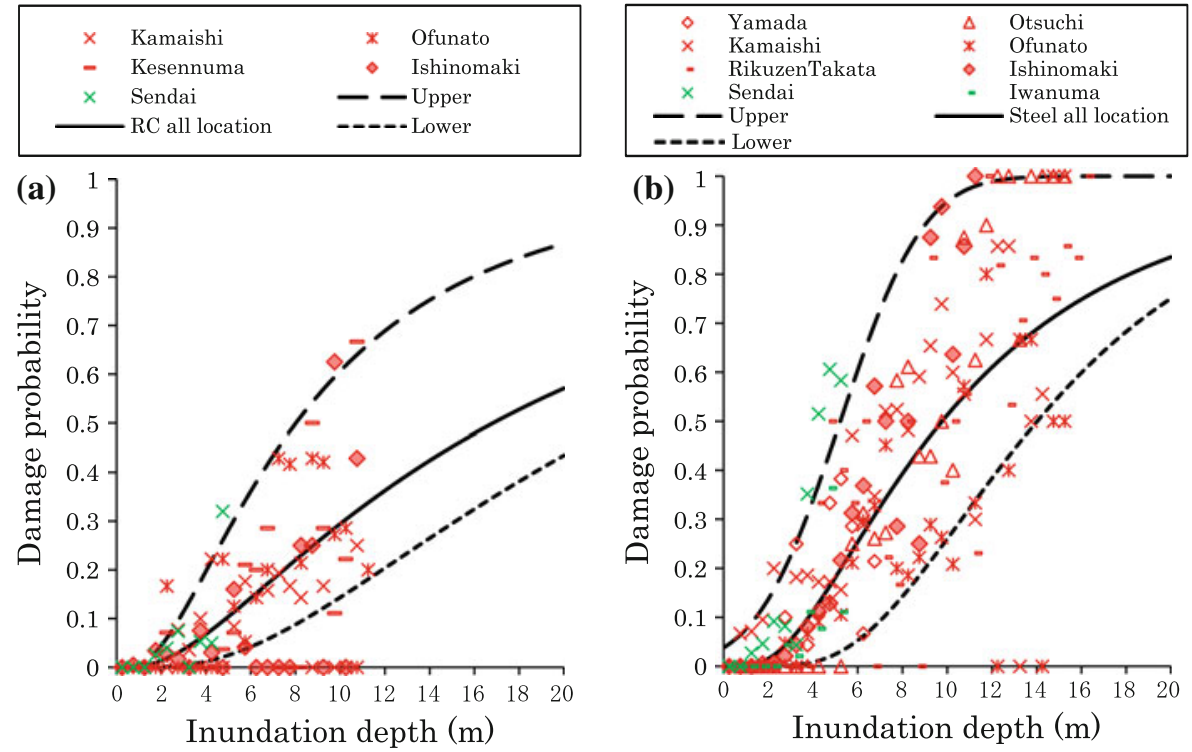

\begin{tabular}{|clcl|}
\hline$\square$ & Miyako & $\diamond$ & Yamada \\
$\Delta$ & Otsuchi & $\times$ & Kamaishi \\
× & Ofunato & - & RikuzenTakata \\
- & Kesennuma & $\circ$ & MinamiSanriku \\
+ & Onagawa & $\diamond$ & Ishinomaki \\
$\square$ & HigashiMatsushima & $\diamond$ & Shichigahama \\
$\Delta$ & Shiogama & $\times$ & Sendai \\
* Natori & Watari & - & Iwanuma \\
- & Shinchi & $\circ$ & Yamamoto \\
+ & MinamiSoma & $\bullet$ & Soma \\
$\Delta$ & Wood all location & $\mathbf{- - - -}$ Lower \\
\hline
\end{tabular}
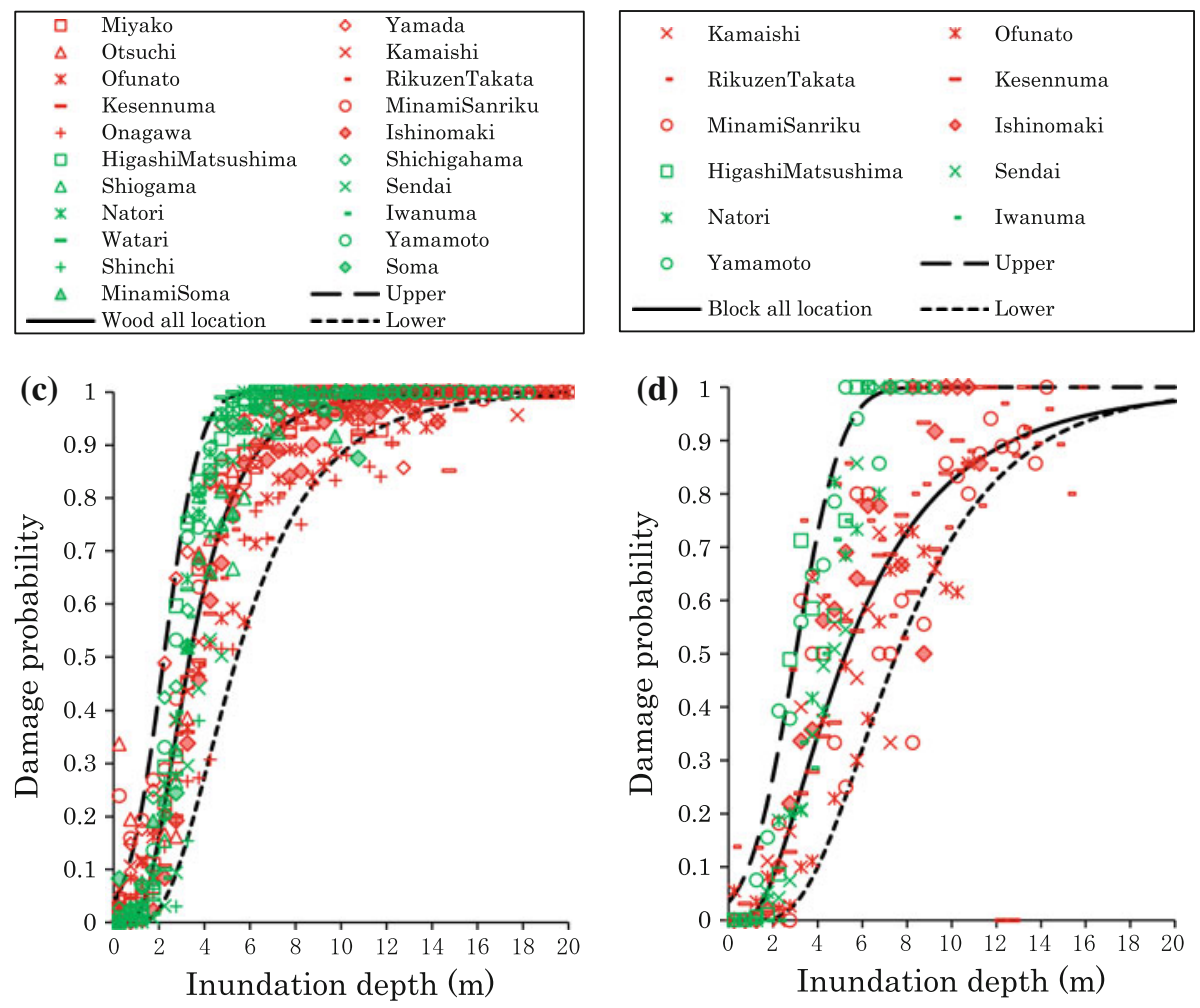

Fig. 7 Comparison of tsunami fragility curves between ria coast and plain coast for washed away building with separated structural material a RC, b Steel, c Wood and d Masonry 


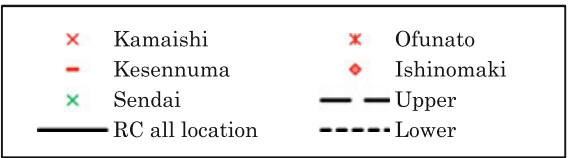

\begin{tabular}{|clll|}
\hline$\diamond$ & Yamada & $\Delta$ & Otsuchi \\
$\times$ & Kamaishi & $*$ & Ofunato \\
- & RikuzenTakata & $\diamond$ & Ishinomaki \\
$\times$ & Sendai & & Iwanuma \\
- & Upper & & Steel all location \\
--- Lower & & & \\
\hline
\end{tabular}
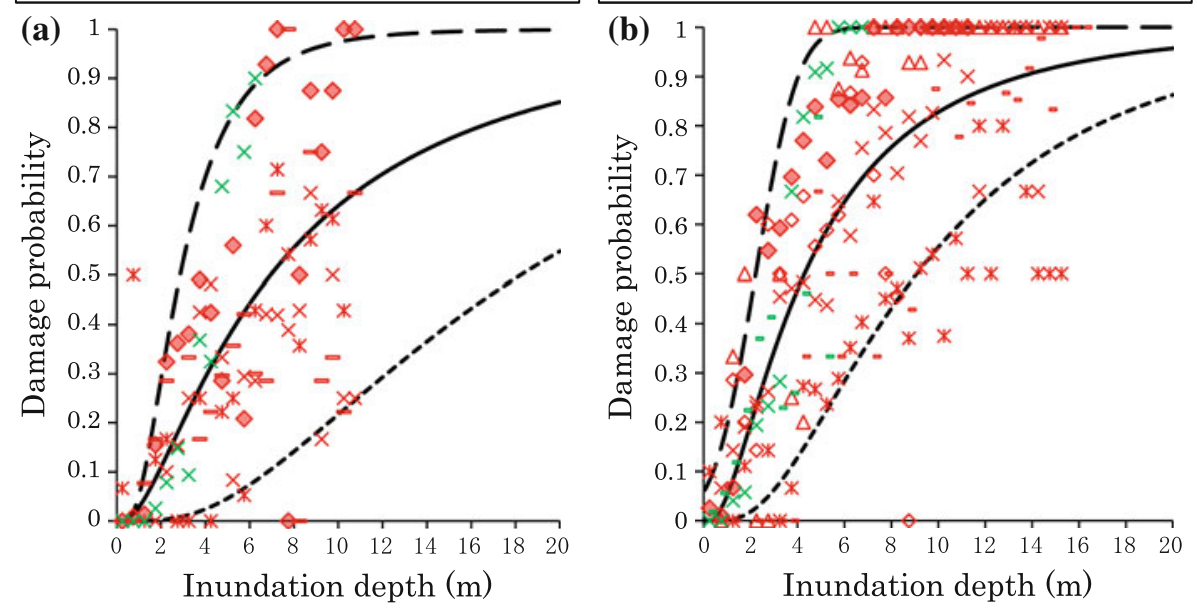

\begin{tabular}{|c|c|c|c|}
\hline$\square$ & Miyako & $\diamond$ & Yamada \\
\hline$\Delta$ & Otsuchi & $x$ & Kamaishi \\
\hline * & Ofunato & - & RikuzenTakata \\
\hline - & Kesennuma & 0 & MinamiSanriku \\
\hline+ & Onagawa & $\bullet$ & Ishinomaki \\
\hline 口 & HigashiMatsushima & $\circ$ & Shichigahama \\
\hline$\Delta$ & Shiogama & $x$ & Sendai \\
\hline * & Natori & - & Iwanuma \\
\hline - & Watari & ० & Yamamoto \\
\hline+ & Shinchi & $\diamond$ & Soma \\
\hline$\Delta$ & MinamiSoma & - & - Upper \\
\hline & Wood all location & -- & - Lower \\
\hline
\end{tabular}
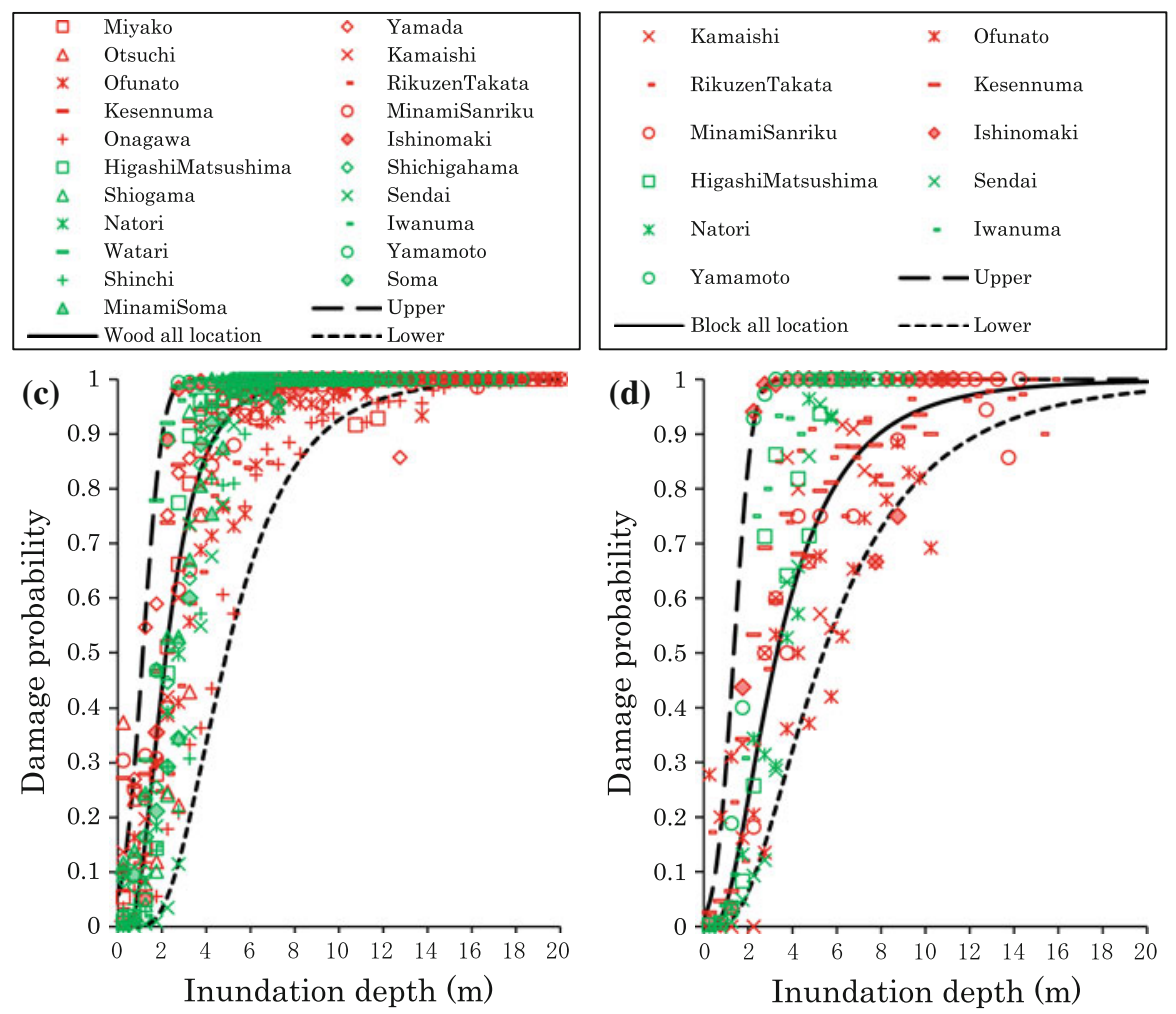

Fig. 8 Comparison of tsunami fragility curves between ria coast and plain coast for collapsed building with separated structural material a RC, b Steel, c Wood and d Masonry 


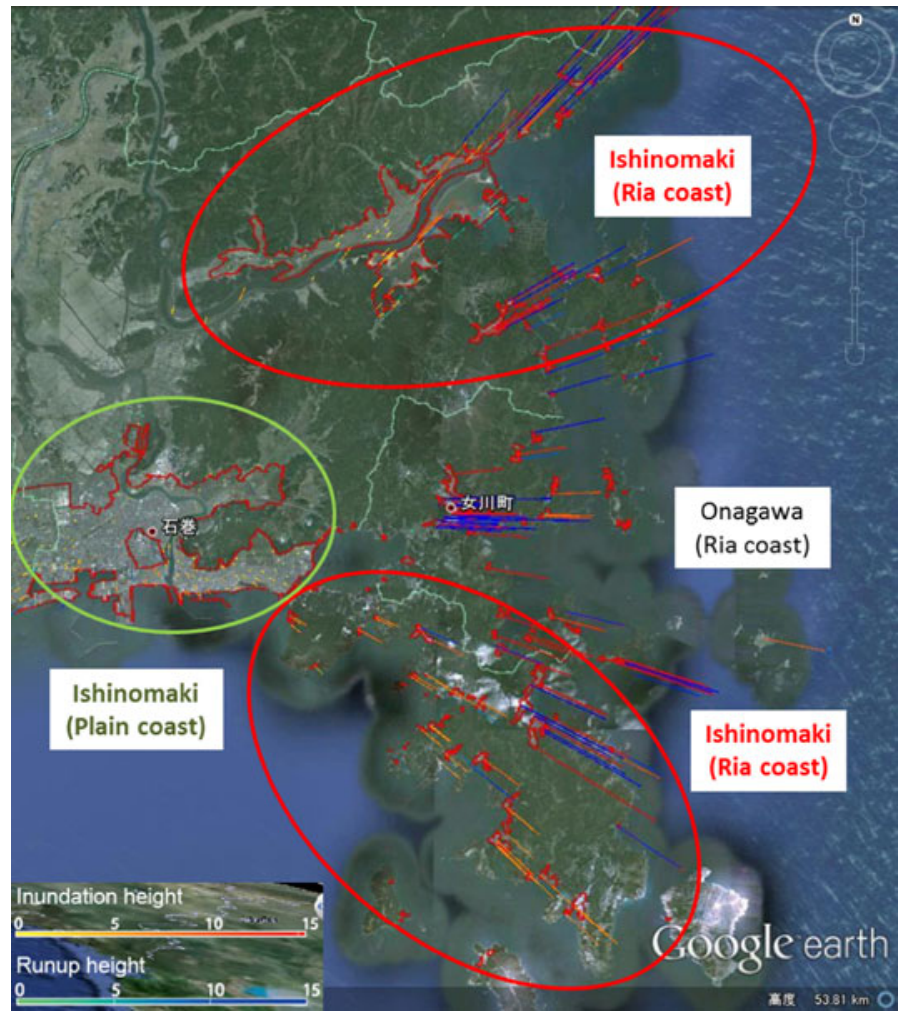

Fig. 9 Area map of Ishinomaki city showing the ria coast and plain coast
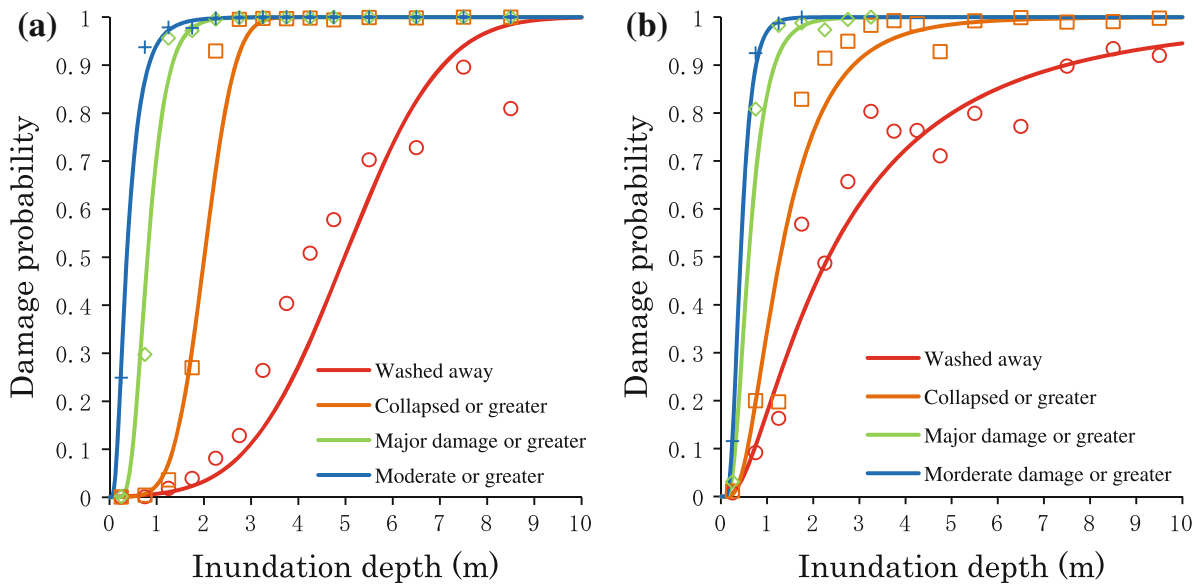

Fig. 10 Tsunami fragility curves using data from Ishinomaki city only (mixed structural material) for a comparison between a Plain coast and $\mathbf{b}$ Ria coast 
structural characteristics on building damage probabilities and provided a very valuable insight into the influence of coastal configuration on building damage. The first part of the analysis was based on damage level, structural material and number of stories; and the next part of the analysis included effects from the coastal topography. The statistical parameters that were derived and used to construct the tsunami fragility curve in this study are summarized in Table 3.

The main findings of this study and their applicability are summarized as below.

- The results show a better resistant performance of reinforced concrete and steel buildings over wood or masonry buildings.

- Buildings taller than two stories were confirmed to be much stronger than the buildings of one or two stories under the same inundation depth.

- It is also found that coastal topography can have a significant influence on building damage. At the same tsunami inundation depth, buildings along the Sanriku ria coast suffered greater damage than buildings from the plain coast in Sendai due to higher flow velocity present in the ria coast.

These are important considerations in designing a tsunami evacuation building and assessing future tsunami risk for land use and evacuation planning. Detailed conclusions for each point highlighted above are presented in the following sections.

\subsection{Damage level}

The inundation depth of $2 \mathrm{~m}$ is a key threshold to classify the building damage due to the tsunami because the probability of reaching any damage state, for all structural material, becomes certain. Wooden house is the most common structure found along Japanese coasts, as a light structure is preferred to reduce the earthquake impact. However, tsunami apparently causes large damage to wooden structures when the inundation depth is more than $2 \mathrm{~m}$. This depth threshold is also considered for the new classification of tsunamiwarning message in Japan. Indeed, a 3-m tsunami height will be considered as one class because 2-m inundation depth can cause serious damage to a wooden house if land elevation in generally assumed equal to $1 \mathrm{~m}$.

\subsection{Structural material}

It is clear that RC and steel structures are less likely to be destroyed that help than wood and masonry buildings, as more than half of them still may survive even with an inundation depth as high as 5-10 $\mathrm{m}$. These results support the idea that the tsunami evacuation refuge should be an RC building. However, other conditions such as building foundation type and openings should be also included for further discussion of exceptional cases. For example, wood buildings may survive if they have strong columns with large openings such as doors and windows at a lower floor, or if they are sheltered by stronger/larger structures.

\subsection{Number of stories}

There are no major differences in damage probability for both $\mathrm{RC}$ and wood buildings between one and two story. Nevertheless, for multistory buildings over three floors, the damage probability is noticeably decreased. The results show that $10-\mathrm{m}$ inundation depth 
Table 3 Summary of parameters for constructing the tsunami fragility curves in this study

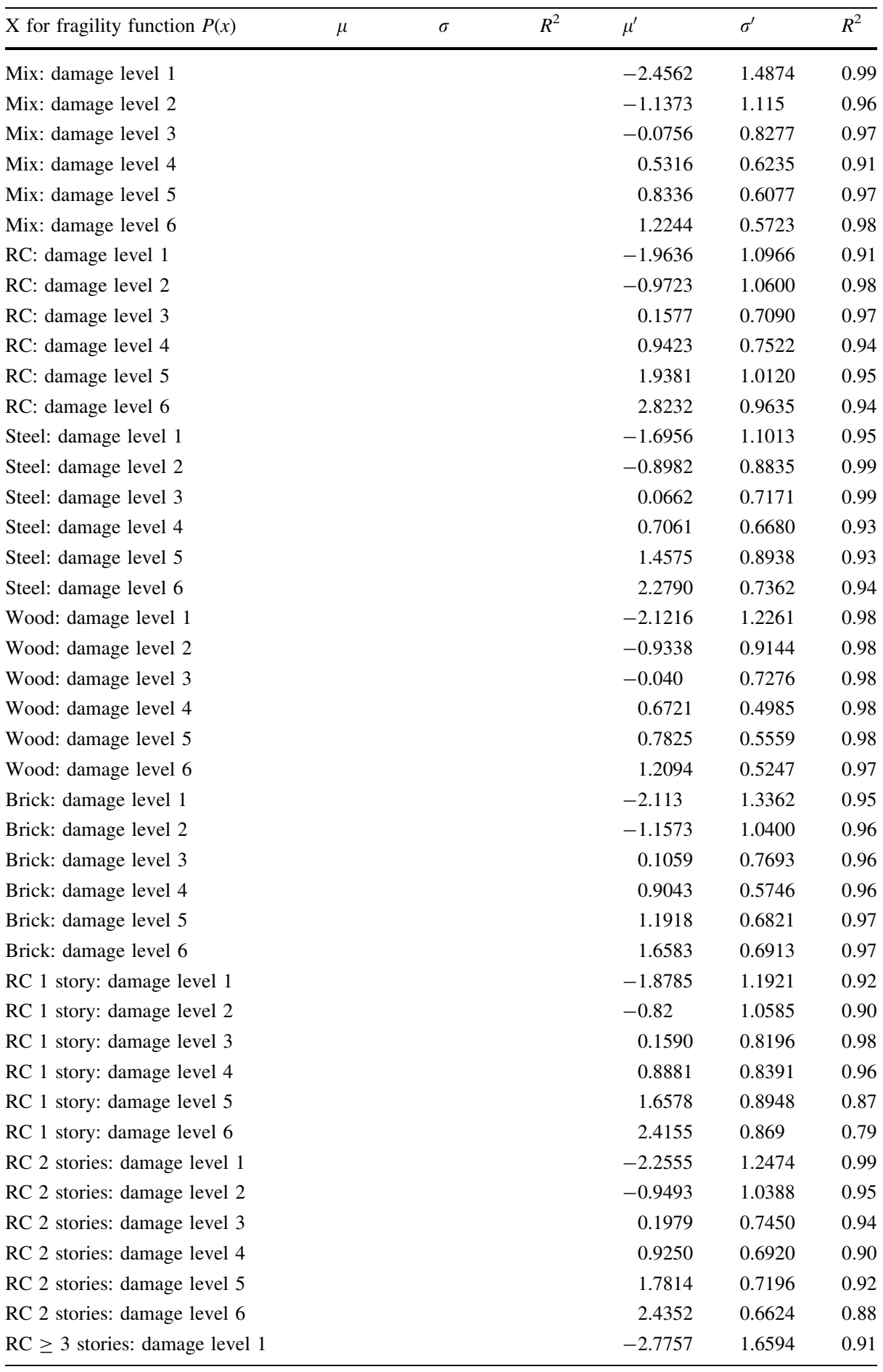


Table 3 continued

\begin{tabular}{|c|c|c|c|c|c|c|}
\hline $\mathrm{X}$ for fragility function $P(x)$ & $\mu$ & $\sigma$ & $R^{2}$ & $\mu^{\prime}$ & $\sigma^{\prime}$ & $R^{2}$ \\
\hline $\mathrm{RC} \geq 3$ stories: damage level 2 & & & & -0.9784 & 1.0220 & 0.97 \\
\hline $\mathrm{RC} \geq 3$ stories: damage level 3 & & & & 0.1489 & 0.6600 & 0.93 \\
\hline $\mathrm{RC} \geq 3$ stories: damage level 4 & & & & 1.1408 & 0.7981 & 0.86 \\
\hline $\mathrm{RC} \geq 3$ stories: damage level 5 & & & & 2.3491 & 0.7898 & 0.72 \\
\hline $\mathrm{RC} \geq 3$ stories: damage level 6 & & & & 2.7121 & 0.4966 & 0.56 \\
\hline Wood 1 story: damage level 1 & & & & -1.7268 & 1.1462 & 0.98 \\
\hline Wood 1 story: damage level 2 & & & & -0.8580 & 0.9395 & 0.98 \\
\hline Wood 1 story: damage level 3 & & & & 0.0481 & 0.7115 & 0.97 \\
\hline Wood 1 story: damage level 4 & & & & 0.6872 & 0.5288 & 0.98 \\
\hline Wood 1 story: damage level 5 & & & & 0.8134 & 0.5941 & 0.97 \\
\hline Wood 1 story: damage level 6 & & & & 1.1733 & 0.5756 & 0.98 \\
\hline Wood 2 stories: damage level 1 & & & & -2.008 & 1.1873 & 0.98 \\
\hline Wood 2 stories: damage level 2 & & & & -0.8747 & 0.9053 & 0.98 \\
\hline Wood 2 stories: damage level 3 & & & & 0.0350 & 0.7387 & 0.98 \\
\hline Wood 2 stories: damage level 4 & & & & 0.7770 & 0.5153 & 0.99 \\
\hline Wood 2 stories: damage level 5 & & & & 0.9461 & 0.5744 & 0.98 \\
\hline Wood 2 stories: damage level 6 & & & & 1.3633 & 0.4710 & 0.96 \\
\hline Wood $\geq 3$ stories: damage level 1 & & & & -2.1900 & 1.3198 & 0.87 \\
\hline Wood $\geq 3$ stories: damage level 2 & & & & -0.8617 & 1.224 & 0.73 \\
\hline Wood $\geq 3$ stories: damage level 3 & & & & 0.1137 & 0.8440 & 0.93 \\
\hline Wood $\geq 3$ stories: damage level 4 & & & & 0.7977 & 0.4734 & 0.87 \\
\hline Wood $\geq 3$ stories: damage level 5 & & & & 1.2658 & 0.6242 & 0.83 \\
\hline Wood $\geq 3$ stories: damage level 6 & & & & 1.7702 & 0.3711 & 0.91 \\
\hline Upper: RC: damage level 6 & & & & 2.0818 & 0.8174 & 0.98 \\
\hline Lower: RC: damage level 6 & & & & 3.1228 & 0.7701 & 0.95 \\
\hline Upper: RC: damage level 5 & & & & 1.0517 & 0.6435 & 0.75 \\
\hline Lower: RC: damage level 5 & & & & 2.9029 & 0.7676 & 0.99 \\
\hline Upper: steel: damage level 6 & 5.2209 & 2.9432 & 0.92 & & & \\
\hline Lower: steel: damage level 6 & & & & 2.6402 & 0.5254 & 0.93 \\
\hline Upper: steel: damage level 5 & 2.2191 & 1.4144 & 0.86 & & & \\
\hline Lower: steel: damage level 5 & & & & 2.2056 & 0.7229 & 0.90 \\
\hline Upper: wood: damage level 6 & 2.2176 & 1.2423 & 0.97 & & & \\
\hline Lower: wood: damage level 6 & & & & 1.6918 & 0.5132 & 0.98 \\
\hline Upper: wood: damage level 5 & 1.1359 & 0.6957 & 0.99 & & & \\
\hline Lower: wood: damage level 5 & & & & 1.5937 & 0.4903 & 0.97 \\
\hline Upper: masonry: damage level 6 & 3.0053 & 1.6459 & 0.94 & & & \\
\hline Lower: masonry: damage level 6 & & & & 2.0208 & 0.4955 & 0.92 \\
\hline Upper: masonry: damage level 5 & 1.3527 & 0.6439 & 0.87 & & & \\
\hline Lower: masonry: damage level 5 & & & & 1.6863 & 0.6498 & 0.97 \\
\hline
\end{tabular}

could wash away RC buildings with damage probability of only 0.2 . Therefore, in addition to being a RC frame structure, this result suggests that tsunami evacuation buildings should be at least 3 stories high. 


\subsection{Coastal topography}

The damage probabilities plotted using data from different tsunami-affected areas show that there is quite big range in estimation of damage probability using the same inundation depth. The upper and lower curves for each damage level and structural material show the uncertainty associated with damage estimation using tsunami fragility curves. The comparison of fragility curves for two different coastal topographies shows that the damage probability in ria coast increases rapidly even for a lower inundation depth. The likely explanation for this phenomenon is the high flow velocities due to their coastal topography that were present in this region when the tsunami hit. Therefore, even at the same inundation depth, the damage level can be higher, due to the strong flow velocity that results in large hydrodynamic forces on each building. These observations strongly suggest that the effects of coastal topography should also be considered for building damage assessment by a future tsunami.

\subsection{Comparison with previous studies}

Comparisons of building damage characteristic with previous findings can be made using wood buildings as an example. Indeed, we expect that wooden buildings construction standards in Japan would lead to more resistance to tsunami loads in comparison with some other countries. A summary of building damage criteria from tsunamis prior to the 2011 event (2004 Indian Ocean, 2006 Java, 2009 American Samoa and 2010 Chile) is shown in Table 4.

In other countries, inundation depth of 1-2 m can cause damage from moderate damage to collapse, while 2- to 3-m inundation depth can wash away a building. Firstly, we observe that the wooden buildings in the plain coast (Sendai-Ishinomaki) were less likely to suffer extensive damage or collapse for small inundation depths, which would confirm the assumption above. It can also be seen from the results that the building damage criteria of the 2011 Japan event (all Tohoku region) are similar when the inundation depth is $2-3 \mathrm{~m}$ but seemed weaker when inundation is $<2 \mathrm{~m}$. This is because the results of the 2011 event

Table 4 Summary of building damage criteria from tsunamis since 2004 (wood)

\begin{tabular}{|c|c|c|}
\hline Tsunami event & Location & $\begin{array}{l}\text { Damage description as a function } \\
\text { of inundation depth }\end{array}$ \\
\hline $\begin{array}{l}2004 \text { Indian Ocean } \\
2006 \text { Java } \\
2009 \text { American Samoa } \\
2010 \text { Chile }\end{array}$ & Various & $\begin{array}{l}1.0 \mathrm{~m} \text { : no damage to moderate damage } \\
1.5 \mathrm{~m} \text { : minor damage to collapse } \\
2.0 \mathrm{~m} \text { : moderate damage to collapse } \\
2.5 \mathrm{~m} \text { : major damage to wash away } \\
3.0 \mathrm{~m} \text { : collapsed or washed away }\end{array}$ \\
\hline 2011 East Japan tsunami & $\begin{array}{l}\text { Plain coast in Sendai } \\
\text { and Ishinomaki }\end{array}$ & $\begin{array}{l}2.5 \mathrm{~m} \text { : minor damage } \\
3.0 \mathrm{~m} \text { : moderate damage } \\
4.0 \mathrm{~m} \text { : major damage } \\
4.5 \mathrm{~m} \text { : complete damage }\end{array}$ \\
\hline 2011 East Japan tsunami & All Tohoku region & $\begin{array}{l}0.5 \mathrm{~m} \text { : minor or moderate damage } \\
1.0 \mathrm{~m} \text { : major damage } \\
2.0 \mathrm{~m} \text { : complete damage or collapse } \\
3.0 \mathrm{~m} \text { : washed away }\end{array}$ \\
\hline
\end{tabular}

The inundations depths for the 2004, 2006, 2009 and 2010 tsunamis have been taken, respectively, from Ruangrassamee et al. (2006), Reese et al. (2007, 2011), Mas et al. (2012a) and Suppasri et al. (2012c) 
include damaged buildings in the Sanriku ria coast that have comparatively large damage probability at low inundation depths as mentioned in the previous section. Comparison with results from the same event developed earlier mainly in the plain coast of Sendai and Ishinomaki also shown that the building data in this study are weaker as the damage probabilities in the plain coasts of Sendai and Ishinomaki are smaller. This is also because of the coastal topography where buildings in the plain coast have experienced comparatively less flow velocities than the Sanriku ria coast (Suppasri et al. 2012d).

Comparisons of results from this study and previous studies show importance of different building damage characteristics influenced by coastal topography. Therefore, not only structural material and number of stories but also coastal topography must be considered before applying a damage criterion (threshold depths) or tsunami fragility curves in future building damage assessment.

\subsection{Limitations and future work}

The large number of buildings in the MLIT data set is crucial for the reliability of the least squares regression analysis (i.e., many studies rely on a small number of data points); however, highly aggregated databases such as this one may not capture certain trends in the data. Building-by-building comparison, if such data were available, would be desirable to compare or refine the results in some areas. Future work in this research field should include the investigation into other physical parameters of the process that might have effect on the building damage such as flow velocity, distance from the sea, building orientation with respect to the sea occupancy type and reduction effect by surrounding buildings (sheltering). Work is currently being carried out in this area, taken into account such effects as sheltering during a tsunami attack. In addition, the damage probability associated with the building function (i.e., individual house, apartment, business office, factory or public building) is also an important factor for further economic loss assessment. Indeed, buildings with a similar functionality mostly share similar structural characteristics, such as structural material and number of stories. For example, in Japan, an individual house is typically 1-2 stories and made of wood or masonry; an apartment can be from higher than two stories made of wood or RC; business offices are mostly tall RC buildings; factories are mostly steel framed with 1-2 stories; and public buildings such as schools and hospitals are mostly RC buildings with 3-5 stories. For public buildings, design consideration for tsunami force was applied as most of them are designated as an evacuation building.

Acknowledgments This research was partly funded by the Tokio Marine \& Nichido Fire Insurance Co., Ltd. through the International Research Institute of Disaster Science (IRIDeS) at Tohoku University, the Willis Research Network (WRN) under the Pan-Asian/Oceanian tsunami risk modeling and mapping project, and the Ministry of Education, Culture, Sports, Science and Technology (MEXT). The authors greatly appreciate questions and comments from reviewers that helped to improve the manuscript.

Open Access This article is distributed under the terms of the Creative Commons Attribution License which permits any use, distribution, and reproduction in any medium, provided the original author(s) and the source are credited.

\section{References}

Arikawa T (2009) Structural behavior under impulsive tsunami loading. J Disaster Res 4(6):377-381 Dominey-Howes D, Papathoma M (2007) Validating the "Papathoma Tsunami Vulnerability Assessment Model" (PTVAM) using field data from the 2004 Indian Ocean tsunami. Nat Hazards 40(1):113-136 
Dominey-Howes D, Dunbar P, Varner J, Papathoma-Köhle M (2010) Estimating probable maximum loss from a Cascadia tsunami. Nat Hazards 53(1):43-61

Foytong P, Ruangrassamee A (2007) Fragility curves of reinforced-concrete buildings damaged by a tsunami for tsunami risk analysis. The Twentieth KKCNN Symposium on Civil Engineering. Jeju, Korea, 4-5 October 2007, S8-47

Gokon H, Koshimura S, Matsuoka M, Namegaya Y (2011) Developing tsunami fragility curves due to the 2009 tsunami disaster in American Samoa. In: Proceedings of coastal engineering conference, Japan Society of Civil Engineers, Morioka, 9-11 November 2011 (in Japanese)

Koshimura S, Matsuoka M, Kayaba S (2009a) Tsunami hazard and structural damage inferred from the numerical model, aerial photos and SAR imageries. In: Proceedings of the 7th international workshop on remote sensing for post disaster response. University of Texas, Texas, United States, 22-23 October 2009 (CD-ROM)

Koshimura S, Namegaya Y, Yanagisawa H (2009b) Tsunami Fragility: a new measure to assess tsunami damage. J Disaster Res 4(6):479-488

Koshimura S, Oie T, Yanagisawa H, Imamura F (2009c) Developing fragility curves for tsunami damage estimation using numerical model and post-tsunami data from Banda Aceh, Indonesia. Coast Eng J 51:243-273

Leone F, Lavigne F, Paris R, Denain J-C, Vinet F (2011) A spatial analysis of the December 26th, 2004 tsunami-induced damages: lessons learned for a better risk assessment integrating buildings vulnerability. Appl Geogr 31:363-375

Lukkunaprasit P, Ruangrassame A, Stitmannaithum B, Chintanapakdee C, Thanasisathit N (2010) Calibration of tsunami loading on a damaged building. J Earthq Tsunami 4(2):105-114

Mas E, Koshimura S, Suppasri A, Matsuoka M, Matsuyama M, Yoshii T, Jimenez C, Yamazaki F, Imamura F (2012a) Developing tsunami fragility curves using remote sensing and survey data of the 2010 Chilean Tsunami in Dichato. Nat Hazards Earth Syst Sci 12:2689-2697

Mas E, Suppasri A, Koshimura S, Imamura F (2012b) Review of tsunami fragility curves developed for countries around the Pacific Rim. In: Proceedings of the 8th APRU research symposium, Sendai, Japan, 20-22 September 2012

Matsutomi H, Harada K (2010) Tsunami-trace distribution around building and its practical use. In: Proceedings of the 3rd international tsunami field symposium, Sendai, Japan, 10-11 April 2010, session 3-2

Matsutomi H, Shuto N (1994) Tsunami inundation depth, current velocity and damage to houses. In: Proceedings of coastal engineering conference, Japan Society of Civil Engineers, 41, 246-250 (in Japanese)

Ministry of Land, Infrastructure and transportation (MLIT): Survey of tsunami damage condition: http://www.mlit.go.jp/toshi/toshi-hukkou-arkaibu.html. Accessed 4 July 2012

Murao O, Nakazato H (2010) Vulnerability functions for buildings based on damage survey data in Sri Lanka after the 2004 Indian Ocean tsunami. In: Proceedings of the 7th international conference on sustainable built environment, Kandy, 13-14 December 2010

National Police Agency (2011) Damage condition of the 2011 earthquake off the Pacific coast of Tohoku http://www.npa.go.jp/archive/keibi/biki/higaijokyo.pdf. Accessed 20 July 2012

Papathoma M, Dominey-Howes D (2003) Tsunami vulnerability assessment and its implications for coastal hazard analysis and disaster management planning, Gulf of Corinth, Greece. Nat Hazards Earth Syst Sci 3:733-747

Papathoma M, DomineyHowes D, Zong Y, Smith D (2003) Assessing Tsunami vulnerability, an example from Herakleio, Crete. Nat Hazards Earth Syst Sci 3:377-389

Porter K, Kennedy R, Bachman R (2007) Creating fragility functions for performance-based earthquake engineering. Earthquake Spectra 23(2):471-489

Reese S, Cousins WJ, Power WL, Palmer NG, Tejakusuma IG, Nugrahadi S (2007) Tsunami vulnerability of buildings and people in South Java - field observations after the July 2006 Java tsunami. Nat Hazards Earth Syst Sci 7:573-589

Reese S, Bradley BA, Bind J, Smart G, Power W, Sturman J (2011) Empirical building fragilities from observed damage in the 2009 South Pacific tsunami. Earth Sci Rev 107:156-173

Ruangrassamee A, Yanagisawa H, Foytong P, Lukkunaprasit P, Koshimura S, Imamura F (2006) Investigation of Tsunami-induced damage and fragility of buildings in Thailand after the December 2004 Indian Ocean Tsunami. Earthquake Spectra 22:377-401

Shuto N (1993) Tsunami intensity and disasters. In: Tinti S (ed) Tsunamis in the world, Kluwer Academic Publisher, Dortrecht, pp 197-216

Suppasri A, Koshimura S, Imamura F (2011) Developing tsunami fragility curves based on the satellite remote sensing and the numerical modeling of the 2004 Indian Ocean tsunami in Thailand. Nat Hazards Earth Syst Sci 11:173-189 
Suppasri A, Koshimura S, Imai K, Mas E, Gokon H, Muhari A, Imamura F (2012a) Field survey and damage characteristic of the 2011 Tohoku tsunami in Miyagi prefecture. Coast Eng J 54:1250005

Suppasri A, Koshimura S, Matsuoka M, Gokon H, Kamthonkiat D (2012b) Remote sensing of planet earth: application of remote sensing for tsunami disaster, InTech, ISBN 979-953-307-541-8

Suppasri A, Mas E, Koshimura S, Imai K, Harada K, Imamura F (2012c) Developing tsunami fragility curves from the surveyed data of the 2011 Great East Japan tsunami in Sendai and Ishinomaki Plains. Coast Eng J 54:1250008

Suppasri A, Imai K, Imamura F, Koshimura S (2012d) Comparison of casualty and building damage between Sanrikuria coast and Sendai plain coast based on the 2011 Great East Japan tsunami. In: Proceedings of international sessions in coastal engineering, JSCE, ed., vol 3

Tohoku Earthquake Tsunami Joint Survey Group (2011) Nationwide field survey of the 2011 off the pacific coast of Tohoku Earthquake Tsunami. J Jpn Soc Civ Eng Ser B 67(1):63-66

Valencia N, Gardi A, Gauraz A, Leone F, Guillannde R (2011) New tsunami damage functions developed in the framework of SCHEMA project: application to European-Mediterranean coasts. Nat Hazards Earth Syst Sci 11:2385-2846 